\title{
Progress report: Vice President's task force on pest control alternatives
}

\section{Overview}

\author{
James M. Lyons a FrankG.Zalom
}

Pest management practices in California's food, fiber, and forest production system are in transition. Though dominated by synthetic organic pesticides in the two decades immediately following World War II, pest control programs recommended by University of California researchers in recent years have incorporated a variety of strategies, resulting in more ecologically balanced, "integrated" approaches to managing pests in many of California's major crops. Despite the reductions in pesticide use that have resulted from these integrated systems, there is increased public and governmental concern about the effects of extensive pesticide use on the environment, the health of farmworkers, and the pests' development of pesticide resistance. Further, the public now perceives that pesticides constitute an involuntary and unacceptable threat to food safety. This last factor has led to a number of legislative and public initiatives that call for alternative approaches to pest control in crop and animal production.

As a result, growers have an urgent need to find alternatives to many chemical pesticides targeted by such legislation, but they fear those alternatives will be unavailable or either more costly or less effective than conventional pesticides. They believe that many government and industry policies, including restrictive cosmetic standards, price supports that encourage maximum use of acreage and production, and incentives for pursuit of specific production practices - most of which were enacted when pesticide use was not subject to such intense public debate - will make the transition to new alternatives difficult.

Research on integrated pest management accelerated in the 1970 s, and the University has focused many scientist-years of effort on the principal goal of developing and promoting the broad array of methods that have successfully allowed California growers to reduce their reliance on synthetic organic pesticides. However, lowering the amount of pesticides applied to agricultural crops is no simple task. Many elements are involved.

Pesticides are generally applied because they work effectively, and both the growers and the people from whom they seek pest management advice have believed these chemicals to constitute a necessary and profitable investment. Pesticides were seen as inexpensive, and their effect upon pest populations was immediate and often dramatic. Producers were able to grow some crops in otherwise unsuitable locations, taking advantage of valuable market niches. Crops could be grown in uniform plantings on large acreages. Farmers could extend their growing seasons to satisfy market demands or to supply local packing or processing industries. Pesticides came into widespread postharvest use as a means of maintaining the quality and extending the shelf life of agricultural products. Consumers enjoyed a high-quality, attractive supply of a great diversity of fresh fruits and vegetables year round.

The decisions leading to these practices were based on the best information available at the time. Growers will only be convinced to use less pesticide if they see well-documented evidence that alternative systems are effective and economical within the context of their own production systems. Implementing the alternative programs must not be much more difficult or time-consuming than maintaining conventional pesticide programs, and the resulting crops must be of an acceptable quality and yield.

What chemical and nonchemical substitutes will be available to replace the pesticides facing restriction under current and proposed regulations? A number of conventional pesticides will remain available because they will be supported by their registrants on specific crops and will meet heaith and environmental requirements for continued use. The herbicide glyphosate, insecticides carbaryl and chlorpyrifos, and the acaricide propargite are notable examples. Several management practices such as crop-free periods, extensive rotations, and various sanitation practices that were once common may again come into widespread use. New pest-resistant cultivars will continue to be developed and released.

Many factors will determine whether these and other available nonchemical alternatives are economically viable or compatible with current production practices that yield products acceptable to the consumer. Some crops will be affected more than others by the loss of specific pesticides. Crops with limited national acreage or relatively low total value will be particularly hard-hit, since registering new pesticides for such crops has always been difficult and expensive. The availability of a specific alternative may be debatable; some alternatives, while promising, have not had adequate development or testing, and their impacts, economics, and availability remain unknown.

In the fall of 1989 Kenneth R. Farrell, Vice President of UC's Division of Agriculture and Natural Resources (DANR), organized a task force to assess some current and proposed laws that would remove certain pesticides from use, and to determine what research and extension activities would best respond to the needs of the food, fiber, and forest production system should it have to adjust to the loss of those materials. It is recognized that issues surrounding pesticide use pose several complex public policy questions related to human health, food safety, the environment, and agricultural productivity. The reports presented in this series deal with only one aspect of these complex issues - the potential impacts of loss of targeted compounds on the efficacy of on-farm pest management. Other researchers, such as Archibald (1990), Winter, Seiber, and Nuckton (1990), and Carter and Nuckton (1988) have addressed aspects of human health and food safety, Hanson and Tanji (1989) and Tanji (1990) have addressed environmental aspects related to water quality, and Seiber et al. (1980) have addressed aspects related to air quality.

The first report in the series that follows was written by Michael Stimmann and Mary Ferguson to analyze the effects of two existing laws - the California Safe Drinking Water and Toxic Enforcement Act of 1986 (Proposition 65) and the Federal Insecticide, Fungicide; and Rodenticide Act as amended in 1988 (FIFRA 1988) - and an initiative measure slated for the November 1990 ballot, the California Environmental Protection Act of 1990 (EPA 1990). Their analy- 
sis identifies those pesticides that are potential candidates for removal from use as a result of these regulatory actions.

In the second, Frank Zalom and Joyce Strand provide a preliminary glimpse of a large database that identifies various alternatives and options currently available for pest control in the absence of those pesticides discussed by Stimmann and Ferguson. The database was developed from the responses to a questionnaire distributed to Cooperative Extension advisors and specialists with pest management responsibilities as well as to Agricultural Experiment Station and USDA-Agricultural Research Service scientists. Data for each crop and pesticide combination include the target pest, alternative pesticides, alternative nonchemical controls, constraints to the rapid adoption of some of these alternatives, and the research agenda needed to develop effective alternatives.

While the questionnaire's excellent response yielded an extensive database, a number of data gaps remain. The pest management departments and specialists are now reviewing the database, seeking to expand and further refine the list of alternatives and to explore the nature of constraints that currently restrict the efficacy of otherwise viable alternatives. The database is also in the process of being analyzed by economists to determine on-farm cost comparisons where they are possible. That analysis will be published as a separate report upon its completion in August.

In the final report of the current series, Mary Louise Flint provides a general description of the various pest management options and a summary of critical areas needing additional, accelerated research for each alternative. A research database developed from the questionnaire described above and from the efforts of subjectarea workgroups categorizes the pest management options as biological, cultural, or chemical in nature. The researchers are now reviewing the database to further define research needs, catalog ongoing research activities, and provide the time-frame for introducing viable alternatives to specific pesticide uses.

This database will be valuable in determining the research agenda and setting priorities for future activities, both for redirection of existing research resources and assigning new funds that may be made available for the development of alternatives to the use of pesticides. For example, the California Environmental Protection Act of 1990 , if approved by the voters, would provide $\$ 20 \mathrm{mil}-$ lion in competitive grants for applied research and extension on alternatives to pesticides in agriculture, including interdisciplinary projects on alternative farming systems, methods, processes, and technologies.

Similarly, another proposed initiative measure, the Consumer Pesticide Enforcement Act for Food, Water, and Worker Safety, authorizes an appropriation of $\$ 5$ million each year for research awards to conduct pest management research projects, with an emphasis on alternatives to pesticides, use of safer pesticides, and farm management practices that result in the reduction of pesticide use or the minimization of pesticide residue. The database developed in our study would help focus these resources on the critical research areas. This initiative has not been included in our series of reports because it does not propose the cancellation of any chemical registrations, and therefore falls outside the scope of this review.

Tom Lanini, Dave Bayer, Becky Westerdahl, Jim Stapleton, Bees Butler, and Karen Klonsky helped design the survey. Lanini, Westerdahl, Stapleton, and Bayer led the discipline workgroups and helped assemble the data. The writers of the IPM Education and Publications Group helped organize and interpret survey responses. Buz Dreyer created the database program, and Christine Spainhower entered the data.

The database on pest control alternatives is the result of the unselfish contributions of the University of California Cooperative Extension and Experiment Station staff, who gave their valuable time to share their knowled ge in the original survey and in workgroup meetings.

\section{Selected references}

Choices, "Regulating chemicals," S. O. Archibald. First Quarter 1990.

Chemicals in the human food chain, C. K. Winter, J. N. Seiber, and C. F. Nuckton. Van Nostrand Reinhold, 1990.

University of California Agricultural Issues Center, "Chemicals in the human food chain: sources, options, and public policy," H. O. Carter and C. F. Nuckton, eds., Symposium, June 2-3, 1988.

Division of Water Quality, State Water Resources Board, "The status of agricultural drainage problems in California, 1989," B. Hanson and K. K. Tanji, August 1989.

Confluence of Change: The Great Central Valley, "Water: stretching the limits," K. K. Tanji, Symposium, May 1990.

Pesticide Analytical Methodology, "Analysis of pesticidal residues in the air near agricultural treatment sites," J. M. Seiber, G. A. Ferreria, B. Hermann, and J. E. Woodrow, American Chemical Society Symposium Series, 136, 1980.

James M. Lyons is Assistant Director of Programs for the Division of Agriculture and Natural Resources, based at Kaiser Center in Oakland and at UC Davis; and Frank G. Zalom is Director, Statewide IPM Project,IPM Implementation Group, and Extension Entomologist, based at UCC Davis.

\title{
Potential pesticide use cancellations in California
}

\author{
Michael W. Stimmann Mary P. Ferguson
}

Increasingly, pesticide registrations are being rescinded by state and federal regulatory actions and by private sector decisions to withdraw pesticide products. Public concern, regulatory complexity, and scientific understanding of the hazards of pesticides are likely to increase in the near future. California faces the potential loss of a large part of the currently employed chemical pest control technology. An understanding of these pesticide losses will help California's agricultural community identify and adopt effective and acceptable alternative pest management techniques and help the University of California make informed decisions on directing its research and extension resources.

We have reviewed the potential impact of two existing laws and one proposed law affecting agricultural pesticide use in California, in order to identify the pesticides that might be targeted for cancellation. These laws are the Safe Drinking Water and Toxic Enforcement Act of 1986 (Proposition 65), the Federal Insecticide, Fungicide, and Rodenticide Act as amended in 1988 (FIFRA 1988), and an initiative measure on the November 1990 ballot, the Environmental Protection Act of 1990 (EPA 1990). The potential impacts of these laws range from a requirement that a warning statement accompany pesticide-treated produce to the partial or complete cancellation of the pesticides' agricultural use.

The three measures may be thought of as a series of progressively more restrictive filters. Pesticide use is currently unaffected under Proposition 65, and many uses of most products will continue beyond the reregistration process required by FIFRA 1988. 